\title{
O Coral Cênico Cidadãos Cantantes: um espaço de encontro entre a música e a saúde
}

\section{The Theatrical Choral Singing Citizens: a place of encounter between music and health}

\author{
Julio Cezar Giudice Maluf ${ }^{1}$, Isabel Cristina Lopes², Tatiana Alves C. \\ Bichara $^{3}$, Juliana Araújo Silva ${ }^{4}$, Isabela Umbuzeiro Valent ${ }^{4}$, \\ Renata Monteiro Buelau ${ }^{4}$, Elizabeth M. F. Araújo Lima ${ }^{5}$
}

\begin{abstract}
MALUF, J. C. G.; LOPES, I. C.; BICHARA, T. A. C.; SILVA, J. A.; VALENT, I. U.; BUELAU, R. M.; LIMA, E. M. F. A. O Coral Cênico Cidadãos Cantantes: um espaço de encontro entre a música e a saúde. Rev. Ter. Ocup. Univ. São Paulo, v. 20, n. 3, p. 199-204, set./dez. 2009.
\end{abstract}

RESUMO: Este artigo relata a experiência do Coral Cênico Cidadãos Cantantes, criado em 1992 como desdobramento das atividades dos Centros de Convivência e Cooperativa da Secretaria de Saúde do Município de São Paulo, com apoio da Associação SOS Saúde Mental, Ecologia e Cultura. O Coral possui uma composição heterogênea, reunindo portadores de sofrimento mental, pessoas em situação de vulnerabilidade e pessoas da população em geral, interessados na construção artística, tendo como local de trabalho as dependências da Galeria Olido da Secretaria Municipal de Cultura de São Paulo. Desde 2006 o Coral estabelece parceria com o Laboratório de Estudos e Pesquisa Arte e Corpo em Terapia Ocupacional. A prática do Coral recupera o sentido da arte como um atributo humano capaz de transformar atitudes, lugares de saber, lugares de existência e, por conseqüência, capaz de alterar a qualidade de vida. A ferramenta de trabalho dos Cidadãos Cantantes é a promoção de encontros nos quais se possa cantar buscando a harmonização das dissonâncias para afinar diferenças e sustentando uma experimentação na interface entre canto coral, arte e saúde na contemporaneidade. A prática musical em grupos que apresentam esse perfil mostra-se, não só possível, como instigadora, para se pensar novas possibilidades para o canto coral, além de propor novos agenciamentos relacionais e territoriais.

DESCRITORES: Música. Arte. Cultura. Saúde mental. Terapia ocupacional. Política social.

\footnotetext{
${ }^{1}$ Regente e docente no Curso de Música da Faculdade de Ciências da Fundação Instituto Tecnológico de Osasco.

${ }^{2}$ Psicóloga.

${ }^{3}$ Docente de Psicologia da Universidade Estadual de Londrina.

${ }^{4}$ Terapeuta ocupacional.

${ }^{5}$ Docente do Curso de Terapia Ocupacional do Departamento de Fisioterapia, Fonoaudiologia e Terapia Ocupacional da FMUSP.

Endereço para correspondência: Rua Cipotânea, 51. CEP: 05508-900 - São Paulo/SP. E-mail: juliomaluf@terra.com.br/beth.lima@usp.br
} 


\begin{abstract}
Abertura
$\mathrm{O}$ Coral Cênico Cidadãos Cantantes vem se reunindo semanalmente, desde 1992, em ensaios abertos, inicialmente no Centro
\end{abstract} Cultural São Paulo e nos últimos anos na Vitrine da Dança da Galeria Olido. Com um repertório de música popular brasileira, canções regionais e outras de autoria de membros do grupo, canta para espantar os males da segregação e encantar com criatividade àqueles que ainda se emocionam com a liberdade, a poesia, o respeito e a multiplicidade da vida, afinal, como diz Tom Zé, "cada homem é sozinho a casa da humanidade"1.

A proposta dos Cidadãos Cantantes é trabalhar em um coletivo de composição heterogênea, com pessoas que gostam de pesquisar, cantar e dramatizar - independente de sua condição social, cultural e de saúde -, assim como com um grupo de profissionais que atuam no campo da saúde e das artes - especificamente dramaturgia, expressão corporal e música vocal -, pois, acredita-se que a partir do convívio com e na diferença, trilha-se o caminho da inclusão sociocultural. Esta forma de trabalhar revela novas relações sociais e de cidadania, pela atuação interdisciplinar de sua equipe e pela construção e divulgação da produção artística que aí se dá.

O Coral foi fundado no contexto da política pública das Secretarias de Saúde e de Cultura do Município de São Paulo (SMS/SP e SMC/SP), no ano de 1992, impulsionado pela experiência das oficinas de música e teatro dos Centros de Convivência e Cooperativas (CECCO) - serviços municipais de inclusão sóciocultural, que trabalham com inúmeras linguagens artísticas e são voltados para a população de um dado território, compondo a rede integral de atenção à saúde da cidade. (LOPES, 1999). Em 1995, perdeu o apoio governamental que possuía e foi adotado pela Associação "SOS Saúde Mental Ecologia e Cultura", associação sem fins lucrativos que passou a viabilizar, quando necessário, transporte, busca de assistência à saúde e orientação de direitos, dada a significativa porcentagem de participantes em situação de vulnerabilidade social. Na época também contou com apoio da Cáritas Arquidiocesana da Sé, para aquisição de instrumentos musicais e material cênico.
A partir de 2000 tornou-se um grupo autônomo, estabelecendo parcerias com o Centro Cultural São Paulo da SMC/SP, com a Cáritas Arquidiocesana Sé e com a Coordenadoria de Saúde da Subprefeitura de Vila Mariana da SMS/SP. Esta última parceria se efetivou através do CECCO Parque Ibirapuera, que disponibilizou profissionais para colaborarem no manejo do grupo, além de acompanharem os ensaios e oferecerem suporte técnico e orientação aos participantes. Hoje são parceiros do Coral, a Associação "SOS Saúde Mental, Ecologia e Cultura", o Centro Cultural Popular da Consolação (CCPC), e o Laboratório de Estudos e Pesquisa Arte e Corpo em Terapia Ocupacional do Curso de Terapia Ocupacional da USP. O Coral conta, ainda, com o apoio da Galeria Olido da SMC/SP.

O trabalho dos Cidadãos Cantantes tem o intuito de integrar a rede de atenção do Sistema Único de Saúde (SUS), qualificando-a em seu caráter intersetorial e transdisciplinar, por meio de ações artísticas para grupos heterogêneos, em espaço cultural. Contribui, assim, para a ampliação do conceito de integralidade em saúde, incluindo a emancipação, o pertencimento, a potência criativa, a participação, o trânsito, o lugar existencial e a ampliação dos laços sociais como indicadores de saúde, sobretudo para os segmentos populacionais em vulnerabilidade (PINHEIRO; MATTOS, 2005). Saúde aqui é associada ao desenvolvimento do potencial criativo e ativo, e à promoção de encontros que qualifiquem as relações entre as pessoas e com o meio ambiente (LIMA, 2006).

É objetivo desse trabalho, também, desenvolver a capacidade de ouvir, falar e agir, favorecendo a instalação de novos recursos individuais e coletivos de autonomia, criatividade, auto-estima e solidariedade. Busca-se, assim, desconstruir práticas de estigmatização e exclusão, demonstrando e incentivando abordagens intersetoriais e transdisciplinares de grupalização que trabalhem de forma cooperativa com a diversidade de seus integrantes.

O nome que designou o grupo nos primeiros anos, de 1992 a 1999, "Coral Cênico da Saúde Mental de São Paulo", estava diretamente relacionado a sua origem e a causa à qual, até hoje se vincula, de construção de uma cultura antimanicomial, pautada na luta pela convivência na diversidade, pelo exercício da cidadania e pelo enfrentamento das instituições totais. Com o passar dos anos, a identificação direta com o campo da saúde

\footnotetext{
${ }^{1}$ Unimultiplicidade, Ana Carolina e Tom Zé. Disponível em: < http://vagalume.uol.com.br/tom-ze/unimultiplicidade.html>
} 
mental, foi se revelando contraditória com a proposta de heterogeneidade do grupo.

A partir do ano 2000, o grupo passou a adotar e denominação "Coral Cênico Cidadãos Cantantes". . A alteração se deu a partir de discussões internas ao próprio grupo e do desejo de seus participantes de vincular sua produção mais claramente ao campo das artes e da cultura que ao campo da saúde. A nova denominação se mostrava mais afinada com os princípios do Coral, marcando uma passagem na maneira deste encarar sua própria atuação e afirmando sua proposta de grupo autônomo e heterogêneo (MALUF, 2005).

Há aproximadamente sete anos o trabalho do Coral foi ampliado com a criação de duas oficinas de sustentação e aprofundamento nas linguagens do corpo: uma oficina de Dança e Expressão Corporal e uma oficina de Teatro, ambas gratuitas e abertas ao público em geral. Esta experiência tem demonstrado a importância de um investimento na expressão artística e sua pluralidade, fundamental para a qualidade atingida no trabalho síntese que o Coral realiza e seu alcance na transformação das vidas.

O grupo conta atualmente com 33 integrantes: destes, três pertencem a equipe técnica: o músico regente, a psicóloga que coordena o projeto, e uma psicóloga que faz a preparação corporal; dois são estagiários e bolsistas do Curso de Terapia Ocupacional (TO); e um músico é colaborador pela parceria com o (CCPC). Há um núcleo mais constante, mas novas entradas são sempre bemvindas, o que exige dos coordenadores e do maestro, uma escuta atenta para que o grupo possa ganhar novas vozes e que uma afinação grupal seja alcançada. Entre sopranos, baixos, contraltos e tenores, os integrantes se encontram e se conhecem e fazem desse espaço um importante lugar de vida e produção de subjetividade.

Os Cidadãos Cantantes compartilham uma vivência provocadora e contraditória: ensaiam em um território aberto e público, uma sala envidraçada no coração da região central da cidade, que facilita o trânsito e a entrada de novos integrantes, mas ao mesmo tempo, experimentam a grupalização em torno do cuidado de seus membros e da valorização de laços de afetividade.

\section{Primeiro movimento: a produção artística e sua aparição nos espaços sócio-culturais}

O Coral configura-se como um espaço de produção e acesso à cultura que oferece, também, atenção e cuidado a um público em estado de vulnerabilidade, promovendo a religação de saberes (MORIN, 2003).

A singularidade deste trabalho reside na multiplicidade de saberes e historias que o atravessam, e particularmente no lócus escolhido para acontecer: o espaço público de circulação das pessoas numa metrópole quase esvaziada de encontros. Provocar encontros implica poder se deparar com o inusitado, com as fraturas ocasionadas pela cidade invisível, pelos sujeitos invisíveis que a habitam. Grupalizar, nesse cenário, é desafiar a tendência ao isolamento e movimentar em espiral, papéis e lugares já dados pela vontade de aprender, criar e transformar. Os Cidadãos Cantantes grupalizam na perspectiva operativa (PICHON-RIVIÈRE, 1986), em que o caráter da tarefa proposta redimensiona a pertinência de múltiplas falas, compatíveis, em sua singularidade, com o contexto de cada obra artística. Na experiência criativa da obra vislumbrase a construção de um novo conceito ético e estético, capaz de instaurar no criador, um campo de significações inexistentes antes dela.

O processo de construção do repertório e os temas que são desenvolvidos em cada programa são discutidos em conjunto e procuram trazer à tona os assuntos que mais interessam aos integrantes do grupo em um dado momento. O repertório, em geral, combina composições ou poesias criadas pelos próprios integrantes do grupo com músicas consagradas na cultura brasileira, provindas do cancioneiro popular, do folclore ou da chamada MPB, e incluindo diferentes estilos, do rock ao rap, do samba à seresta, da música profana à religiosa. A inclusão de canções originais ou poesias de autoria dos integrantes, além de momentos "solo" - no qual um integrante canta, fala um texto, toca um instrumento ou dança - teve grande importância no processo grupal, ao valorizar a capacidade de cada um, mudando o foco do campo da loucura e exclusão, para o campo da criação e constituição de território.

A discussão a respeito do tema a ser abordado e seu desenvolvimento inclui a participação de todos, e são momentos plenos de descobertas, pois existe uma grande abertura para a vazão dos desejos e sonhos de cada um. É um momento em que todos podem fazer uso da palavra para expressar suas vontades e sentimentos, configurando um exercício cotidiano de tolerância, que busca coadunar

\footnotetext{
${ }^{2}$ O termo "Cidadãos Cantantes" é uma homenagem ao coreógrafo brasileiro Ivaldo Bertazzo, que desde os anos 1970 desenvolve em São Paulo um trabalho de dança que não inclui apenas bailarinos, mas sim "Cidadãos Dançantes" (MALUF, 2005).
} 
as forças criativas e os desejos nos planos individuais e coletivos. No exercício dessa conversa franca, todos os assuntos são levantados, da doença ao estigma, da ação política à ação cotidiana, das dores às alegrias.

Esse processo de pesquisa e construção de repertório pode ser entendido como um processo de composição, feito a partir das necessidades e possibilidades do grupo. Para Kerr (1989), o regente, à frente da sua comunidade, é o

articulador dos sons, identificador das capacidades musicais, animador do exercício musical, ativador da memória musical da comunidade e das pessoas. (...). Ao organizar o som possível, o regente se exercita como compositor. Ao liderar as disponibilidades, ele se exercita como regente (p. 15).

A disponibilidade de ouvir o coro, para se construir o programa, é o exercício cotidiano que se busca no trabalho com o Coral Cênico Cidadãos Cantantes. Trata-se de um projeto sonoro oriundo da articulação da vivência do regente com a possibilidade da escuta da comunidade. (KERR, 2006)

Revendo os roteiros musicais do Coral Cênico, e extraindo-se uma lista dos temas que foram abordados nos diferentes programas realizados no período de 1996 a 2008 , pode-se notar que o tema da loucura e seu estigma foram, gradativamente, deixando de ocupar o primeiro plano na montagem. Isto ocorreu à medida que o grupo se tornou mais heterogêneo e a luta antimanicomial passou a ser vista e trabalhada de maneira ampla, como um desafio de desinstitucionalização da diferença, de não segregação de desejos, de despatologização da diversidade, de qualificação da criação e da emergência de sujeitos e sentidos.

A primeira apresentação pública do Coral aconteceu em setembro de 1992, no Centro Cultural São Paulo. Desde 1997, organiza o "Encontro Musical em Defesa da Cidadania Plena", evento que acontece anualmente no Centro Cultural São Paulo e Galeria Olido, durante as comemorações da Semana da Luta Antimanicomial. Como anfitrião do Encontro, o Coral apresenta-se ao lado de outros grupos convidados, que trazem propostas artísticas diversas: corais universitários, de empresas, grupos vocais, grupos folclóricos, grupos indígenas, bandas. Esse encontro marca a abertura oficial de uma nova temporada para o grupo, que prepara para ele uma montagem, que se constituirá no repertório do ano.

Além de utilizar a Galeria Olido como espaço de apresentação, o grupo mostra seu trabalho em diversos locais, já tendo se apresentado em universidades, encontros de corais, eventos e simpósios ligados à inclusão, educação, saúde e cultura, teatros, bibliotecas, auditórios ou na rua. Também recebe, em seus ensaios, a visita de outros grupos de corais.

Em 2009 o Coral Cênico Cidadãos Cantantes foi um dos ganhadores do prêmio Loucos pela Diversidade, da Secretaria da Identidade e da Diversidade Cultural do Ministério da Cultura (SID/MinC), em parceria com a Fundação Oswaldo Cruz do Ministério da Saúde (Fiocruz/ MS). Segundo movimento: a parceria com a TO e a
participação dos estagiários na equipe

A partir de 2006, o Coral Cênico Cidadãos Cantantes e o Laboratório de Estudos e Pesquisa Arte e Corpo em Terapia Ocupacional da USP estabeleceram uma parceria, instaurando um campo de integração entre as atividades de ensino, pesquisa e extensão desenvolvidas pelo Laboratório e a prática inventiva do Coral. A composição desta parceria ampliou o espaço de atuação e formação em Terapia Ocupacional (TO) no campo social, artístico e cultural. A prática com a linguagem musical com um público que poderia estar confinado a espaços convencionais de tratamento, potencializa a formação, conectando-a com propostas arrojadas e inovadoras que se fazem hoje na interface das artes e da saúde.

A participação dos estudantes de TO nas atividades do Coral, compõe o estágio "Terapia Ocupacional e as ações na interface arte e saúde", oferecido aos alunos do $4^{\circ}$ ano do Curso de Terapia Ocupacional da USP. A prática no Coral é acompanhada em grupos de estudo e supervisão, além da realização de reuniões de planejamento e avaliação que integram profissionais e estagiários do Coral e do Curso de TO.

Ao refletirem sobre sua experiência no Coral, os estudantes, freqüentemente discutem a forma de organização dos espaços de arte e cultura da cidade de São Paulo, que muitas vezes dificulta a participação de "pessoas comuns". Apontam, também, a escassez de espaços públicos de cultura, arte e lazer preparados para acolher aqueles que, de alguma forma, não correspondem aos modelos normalizados de sociabilidade, considerando que, para algumas pessoas, participar desses espaços com autonomia é um desafio que precisa ser acompanhado e sustentado pelas equipes responsáveis.

Os estudantes procuram observar e participar do funcionamento do grupo e da equipe buscando encontrar aí seu espaço de ação, Atentos às demandas singulares 
de cada participante, têm a possibilidade de auxiliar a equipe a acolher e organizar demandas sociais e de saúde, agenciando redes, e preparar o grupo para a imersão na experiência musical.

As conversas antes do início do ensaio são interessantes formas de saber o que está acontecendo na vida de cada participante. Alguns participantes possuem demandas importantes que precisam ser escutadas e cuidadas fora do coral. A presença do estagiário na equipe tem sido uma maneira de ampliar essa escuta e, como conseqüência, o cuidado, que não se resume ao encaminhamento para serviços de saúde, mas também se expressa em um olhar mais atento e compreensivo aos movimentos daquele pessoa dentro do grupo.

Na perspectiva da construção artística, os momentos que antecedem ou sucedem os ensaios são, em geral, muito ricos, quando se dão encontros e trocas de experiências que podem indicar afinidades musicais e pessoais para gerar afinação entre os membros do grupo. São momentos privilegiados de escuta por parte do regente e da coordenação, em que se pode observar formações espontâneas entre os integrantes e iluminações que ajudam a clarear os caminhos musicais e artísticos que o grupo irá seguir, quando atravessamentos de temas exteriores ao universo musical podem ser incorporados ao trabalho que está sendo realizado. Para o projeto, a questão fundamental é construir um espaço de acesso igualitário e inclusivo à cultura, um espaço para cantar, fazer música e criar.

O manejo das diversas situações e atravessamentos do processo se dá preferencialmente através da linguagem musical: um gesto do regente ou um som no espaço são suficientes para organizar o grupo, as sonoridades, os corpos em movimento e a dinâmica de trabalho. A atenção aos pequenos detalhes e à presença e organização corporal para que o som saia com qualidade faz parte das ações da equipe. Os estudantes participam da experimentação musical e aos poucos vão aprimorando sua qualidade de canto, atravessados pela musicalidade que envolve o ambiente.

\section{Coda, para finalizar}

O Coral é um lugar de invenção sonora que abre para seus participantes - independentemente de sua condição social ou diagnóstica - o acesso à arte. Um lugar que integra pessoas, histórias, músicas, cenas, num processo de criação compartilhado, entre o grupo e com a comunidade, nas apresentações e nas reverberações no entorno dos participantes. A proposta artística do Coral caracteriza-se pela busca de um trabalho com o que não é hegemônico - sejam harmonias, sejam formas de vida -, experimentando o que as pessoas podem e trazem. Ali, as pessoas cantam simplesmente e a técnica vai aparecendo aos poucos, quando desejada e necessária. O mais importante é a possibilidade que se abre para construir com o corpo e suas sonoridades, uma cena, uma música.

A atividade do Coral se faz a partir de um pacto com a criação e com o aprofundamento nas linguagens artísticas, que revela, ao mesmo tempo, o potencial de cuidado desta prática, com benefícios que são extensivos a todos os envolvidos: coordenação, estagiários, participantes, público. A experiência demonstra que é possível transitar entre a produção cultural e produção de cuidado, de forma que as duas abordagens coexistam, sem que uma se sobreponha a outra, atuando na contramão da tendência contemporânea de esgarçamento do tecido social (LUZ, 2005).

A produção artística do Coral Cênico se coloca entre as diversas expressões de grupos minoritários que, muitas vezes, circulam fora da cultura hegemônica. BARBOSA (1998) adverte para a importância dessas manifestações serem reconhecidas como produção cultural de interesse coletivo. Mas interessa que este reconhecimento não se dê de forma categorizada, pois, como sinaliza PELBART (1998), diferenciar-se no fechamento em um tipo específico de manifestação, acaba instaurando uma outra forma de clausura. O compartilhamento é fundamental e é no desejo das diferenças que a arte busca seu alimento, não pelo interesse no exótico, mas pelas relações novas que podem ser criadas a partir da abertura ao outro que a arte propõe (LIMA, 2003).

A ferramenta de trabalho dos Cidadãos Cantantes é a promoção de encontros nos quais se possa cantar buscando harmonizar dissonâncias e afinar diferenças, para produzir uma sonoridade própria, profundamente trabalhada. A diferença que não é negada, num grupo intencionalmente heterogêneo, acrescenta molho à obra e produz novos conhecimentos e novos sentidos para a vida. Assim como a arte pode estar acessível a todos, a felicidade, a saúde, os direitos também devem e podem estar ao acesso de todos.

Trabalha-se, aqui, na perspectiva do acesso a um novo código cidadão, forjado na convivência e produção artística conjuntas, em que a identidade grupal passa a ser definida pelo mote que agrega a todos: cantar, realizar uma produção artística, na qual cada um se reconhece e se faz conhecer pelo seu nome e sua criação e não pelo diagnóstico ou condição social.

Esta prática recupera o sentido da arte como um atributo humano capaz de transformar atitudes, lugares do 
saber, lugares de existência e, por conseqüência, capaz de alterar a qualidade de vida.

MALUF, J. C. G.; LOPES, I. C.; BICHARA, T. A. C.; SILVA, J. A.; VALENT, I. U.; BUELAU, R. M.; LIMA, E. M. F. A. The Theatrical Choral Singing Citizens: a place of encounter between music and health. Rev. Ter. Ocup. Univ. São Paulo, v. 20, n. 3, p. 199-204, set./dez. 2009.

\begin{abstract}
This article presents the experience of the Theatrical Choral Singing Citizens, created in 1992 as an extension of the activities developed at the Convivence and Cooperative Centers of the Health Secretary of São Paulo, and supported by the NGO "SOS Mental Health, Ecology and Culture". The Choral is a heterogeneous group formed by interest on artistic construction, which gather people suffering from mental illness, people in vulnerability, and others from general population, having been established as a workplace Galeria Olido, in São Paulo. From 2006, the Choral has worked in a partnership with the Laboratory of Studies and Research in Art, Body and Occupational Therapy. This practice recovers the sense of art as a human attribute capable of transforming attitudes, knowledge spaces, and existential spaces in orther to alter one's quality of life. The Coral's tool is the promotion of encounters in which the singers could harmonize dissonances and tune differences, supporting an experience on the interface between choral singing, art and health on contemporaneity. Musical practice in groups who present this profile installs itself, therefore, not only as possible, but instigative in fomenting new possibilities for choral music, new establishment of relations and territories.
\end{abstract}

KEY WORDS: Music. Art. Culture. Mental health. Occupational therapy/trends. Public policy.

\section{REFERÊNCIAS}

BARBOSA, A. M. Tópicos utópicos. Belo Horizonte: C/ Arte, 1998.

KERR, S. Carta coral. In: LAKSCHEVITZ, E. (org). Ensaios: olhares sobre a música coral brasileira. Rio de Janeiro: Centro de Estudos de música Coral, 2006

KERR, S.; BREIM, R.. Monitores corais. São Paulo: Secretaria de Estado da Cultura, 1989.

LIMA, E. M. F. A. Desejando a diferença: considerações acerca das relações entre os terapeutas ocupacionais e as populações tradicionalmente atendidas por estes profissionais. Rev. Ter. Ocup. Univ. São Paulo, v.14, n. 2, p. 64-71, 2003.

LIMA, E. M. F. A. A saúde mental nos caminhos da terapia ocupacional. Mundo Saúde, v. 30, n.1, p. 117-122, jan.-mar. 2006.

LOPES, I. C. Centros de Convivência e Cooperativas: Reinventando com arte agenciamentos de vida. In: FERNANDES. M. I. A (org). Fim de século: ainda manicômios? São Paulo: Instituto de Psicologia da Universidade de São Paulo, 1999. p.139-62.
LUZ, M. T. Fragilidade social e busca de cuidado na sociedade civil de hoje. In: PINHEIRO, R.; MATTOS, R. A. (orgs.). Cuidado: as fronteiras da integralidade. Rio de Janeiro: Cepes/UERJ, Abrasco, 2005. p. 9-20.

MALUF, J. C. G. Afinando diferenças: o processo de construção artística do Coral Cênico Cidadãos Cantantes (1996-2004). 2005. 382 f. Dissertação (Mestrado em Música). Instituto de Artes da Universidade Estadual Paulista "Júlio de Mesquita Filho". São Paulo, 2005.

MORIN, E. Religar a ciência e os cidadãos. In: PENA-VEJA, A. (org). Edgar Morin: ética, cultura e educação. São Paulo: Cortez, 2003.

PELBART, P. P. Teatro nômade. Rev. Ter. Ocup. Univ. São Paulo, v. 9, n. 2, p. 62-69, maio/ago, 1998.

PICHON-RIVIÈRE, E. O processo grupal. São Paulo: Martins Fontes, 1986.

PINHEIRO, R.; MATTOS, R. A. (orgs.). Cuidado: as fronteiras da integralidade. Rio de janeiro: Cepes/UERJ, Abrasco, 2005. 